\title{
ESTUDO DA DETERMINAÇÃO DAS NECESSIDADES DE PROFESSORES: O CASO DO NOVO ENSINO MÉDIO NO BRASIL- ELEMENTO NORTEADOR DO PROCESSO FORMATIVO (INICIAL/CONTINUADO)
}

\author{
Isauro Beltrán Nuñez \\ Professor da Universidade Federal do Rio Grande do Norte, Brasil \\ Betânia Leite Ramalho \\ Professora da Universidade Federal do Rio Grande do Norte, Brasil
}

\section{INTRODUÇÃO}

Os estudos mais recentes sobre as atividades dos professores como profissionais (Pórlan, 1989; Furió, 1994; Perrenoud, 2001; Nóvoa, 1992; entre outros), vêm mostrando a importância da prática como ponto de partida, de chegada e de transformação da atividade profissional. É portanto desta prática, que são reveladas as necessidades formativas como necessidades sócio-historicamente determinadas, contextualizadas, que se dão numa dinâmica dialética. Assim que são os problemas diagonosticados pelos(as) professores(as) em serviço ou em processo de formação, a respeito de sua prática profissional ou pré-profissional, que permite que sejam diagnosticadas as necessidades que devem ser objeto integrador da formação.

A Reforma Curricular para o Ensino Médio no Brasil apóia-se em princípios que caracterizam uma verdadeira "revolução" nas formas de pensar o ensino, a aprendizagem, a educação, no contexto escolar, inserida no movi mento internacional de mudar a escola no século XXI (Delors, 2000). O "Novo Ensino Médio", como tem se denominado esse nível de escolaridade, sugere dialogar com as exigências de uma nova sociedade, gerado no âmbito das transformações tecnológicas, econômicas, das novas formas de produção do conhecimento; da globalização, não só das econômicas, como também do conhecimento. Esse movimento de mudanças na educação traz consigo outras tantas competências profissionais a serem adquiridas pelos professores, novas formas de organização do tempo e do espaço escolar, assim como a compreensão a respeito do papel da escola, centrada "na vida", preocupada com a cidadania, com a inclusão escolar, sobretudo quando as contradições e desigualdades são aguçadas no abismo que separa os diferentes segmentos da sociedade.

As novas competências profissionais dos professores que emergem das Reformulações Curriculares exigem a busca de referências que possam nortear os processos formativos dos docentes, no contexto dos Programas de Desenvolvimento Profissional, que assumem os coletivos de professores face aos novos desafios profissionais.

Assim que pensar num programa formativo de professores em serviço àluz das novas tendências, é de fundamental importância perguntar-se: por onde começar? Na resposta a essa pergunta, diagnosticar e trabalhar necessidades dos professores é uma tarefa a ser prioritária. É nesse contexto que se insere o 
Beltrán, Isauro y Leite, Betânia: Estudo da determinação das necessidades de professores...

presente estudo, desenvolvido com um grupo de professores de um Centro do Ensino Médio na cidade do Natal, no Nordeste do Brasil.

\section{REFLEXÃo TEÓRICO-METODOLÓGICA A RESPEITO DAS NECESSIDADES}

Os estudos sobre as necessidades formativas dos professores estão associados æ̀ pesquisas sobre o desenvolvimento profissional dos professores. As necessidades formativas dos professores se constituem num campo necessário e ainda pouco explorado nos processos de sua formação inicial e continuada.

Segundo Rodrigues e Esteves (1993), a palavra necessidade é uma palavra polissêmica, marcada pela ambigüidade. Já para Burton e Merrill (1977) necessidade é um conceito polimorfo que adapta diferentes acepções segundo seu uso pelos educadores, sociólogos, economistas, trabalhadores sociais, etc. Para Zabalza (1998), uma necessidade é instituída pela discrepância que se produz "entre a forma como as coisas deveriam ser (exigências), poderiam ser (necessidades de desenvolvimento) ou gostaríamos que fossem (necessidades individualizadas) e a forma como essas coisas são de fato" (p.62). A diferença entre o estado atual de desenvolvimento e o estado desejado, dentre outros fatores, determina a necessidade.

$\mathrm{Na}$ linguagem corrente, este termo é usado para designar fenômenos diferentes, tais como desejo, vontade, aspiração, precisando alguma coisa ou alguma exigência. A necessidade tem existência no sujeito que a sente e é fonte de motivações para desenvolver determinados tipos de atividades.

Montero (in Marcelo, 1992, p. 67-68), define o construto "necessidade formativa" como o conjunto de desejos, problemas, carências e deficiências encontradas pelos professores no desenrolar do seu ensino.

Para Blair e Large (1990, p. 146), uma necessidade "define-se pela discrepância entre o que é (a prática habitual) e o que deveria ser (a prática). Portanto, as necessidades devem ser levadas em conta em função de metas específicas".

Vemos o conceito de necessidade no(a) professor(a) como algo útil, imprescindível num momento dado desejável, ligado a valores, que parte de experiências anteriores, definem a procura de algo que falta para poder, conscientemente, fazer o trabalho docente com maior profissionalismo. Estas necessidades são individuais e/ou coletivas, o que permite dirigir a formação do professorado face a novas tarefas da prática profissional. As necessidades docentes têm sua origem na prática, assim que, como categoria norteadora, faz-se necessário pesquisar a prática do(a) professor(a), seu cotidiano na sala de aula e na escola, enquanto profissional e pessoa que ele é.

As necessidades estão vinculadas aos interesses. Esse vínculo, por vezes, é necessário ser construído, na dinâmica do aparecimento de novos interesses. Os conhecimentos que tem os professores, 
Beltrán, Isauro y Leite, Betânia: Estudo da determinação das necessidades de professores...

como conseqüência de suas diferentes concepções, não são só resultado do elemento cognitivo, mas também são de seus interesses como indivíduos que pertencem a um grupo social. Assim que, face à realidade do sujeito, como membro desse grupo, ele adota determinadas condutas, não só por ter uma dada racionalidade, mas também por apresentar determinados interesses (conscientes ou no plano inconsciente), etc. As necessidades surgem das relações complexas na dinâmica entre esses fatores, em que o cognitivo não pode ser separado do afetivo.

Para Zabalza (1998) as necessidades podem ser: prescritivas, individualizadas e de desenvolvimento.

$>$ Necessidades prescritivas, dá-se:

- através da classificação do marco geral de espectativas para o projeto pedagógico, análises do documento, o que se pretende no projeto pedagógico.

$>$ Necessidades individualizadas, refere-se à:

- constatação dos desejos dos sujeitos que participarão;

- formulação de hipóteses de cursos que, a partir de distintos pontos de vista, se ajustarão aos sujeitos, à discussão reflexiva;

- alternativas individualizadoras e marcas de opcionalidade para os participantes.

$>$ Necessidades de desenvolvimento, questiona-se:

- que coisas poderão ser feitas, que poderá ser conseguido além dos mínimos previstos.

- que experiências colaterais poderão otimizar tanto o processo, como os resultados.

Hewton (1998) estabelece diferentes níveis e categorias para o tipo de necessidades de formação identificadas pelos professores:

a) necessidades relativas aos alunos: problemas de aprendizagem, motivação, disciplina, heterogeneidade, avaliação.

b) Necessidades relativas ao currículo: novos planos curriculares levam a novas necessidades de formação de professores.

c) Necessidades dos próprios professores: mais ligadas àabordagem dos professores como profissionais e como pessoas, do que ao ensino. Exemplo: redução da ansiedade.

d) Necessidades da escola/instituto enquanto organização: necessidades que a instituição impõe ao trabalho do professor.

Este estudo centra seu interesse nas necessidades de desenvolvimento, por tratar esta, dos procedimentos que permitem diagnosticar ou caracterizar novas necessidades do professorado.

A análise das necessidades educativas, como área de pesquisa, fez o seu aparecimento no final dos anos 60. Desde então, vem sendo utilizado como um instrumento fundamental no planejamento e tomada de decisão na área educativa. Isto obedece a uma preocupação com a racionalização dos 
Beltrán, Isauro y Leite, Betânia: Estudo da determinação das necessidades de professores...

processos formativos e os desejos de conseguir planos mais estruturados e eficazes que respondam adequadamente às exigências sociais, na intenção de encontrar procedimentos mais eficientes na formação do professor. (Rodrigues e Esteves, 1993).

Uma formação de professores sem direção e sem conhecimento das suas necessidades reais, não ajusta-se às mudanças, que exigem cada vez mais uma ação criadora na preparação dos professores na perspectiva da profissionalização (Ramalho e Nuñez, 2001).

Bridget Somekh (citado em Rodrigues e Esteves, 1993), num estudo sobre a pesquisa-ação e o desenvolvimento colaborativo das escolas, defende a importância de articular as necessidades dos professores com a gestão escolar e suas práticas curriculares. Afirma o autor que,

"O fato das necessidades de formação serem identificadas pelos professores, em ligação estreita com o desenvolvimento curricular e a organização da escola, favorece a participação dos diversos atores na vida da instituição e a emergência de práticas democráticas" (p. 161).

Nesse contexto, a formação de professores é um tipo de atividade permanente, sistematizada e planejada, fundamentada nas necessidades reais e na perspectiva da profissão, orientada à uma formação de competências, de atitudes, de qualidades da personalidade do(a) futuro(a), ou do(a) professor(a) em serviço, a fim de objetivar um programa formativo que leve em conta o nível dos professores, suas experiências, necessidades, tanto particulares como coletivas, que emanam da prática.

A origem das necessidades formativas, ou seja, a necessidade de formar determinadas competências, saberes, etc. não pode situar-se só nos indivíduos, mas também nas instituições onde desenvolvem ou desenvolverão suas atividades, dentro do contexto da sociedade. A determinação das necessidades dos professores como uma das categorias estruturantes dos programas formativos deve levar em conta o fato de em determinadas vezes, a necessidade não se revelar em razão do desconhecimento que os próprios professores possuem a respeito da natureza de novas exigências do trabalho profissional. Por isso, faz-se necessário a reflexão da prática orientada por perspectivas teóricas que possibilitem questionar a própria prática e dar origem a novas necessidades para o aperfeiçoamento do trabalho profissional. As novas exigências do século XXI que vêm sendo traduzidas nas reformas do sistema educativo impõem rupturas profundas no agir profissional do professor que, consequentemente, exige novas necessidades formativas.

Shostak (citado em Marcelo, 1992), definiu os Centros de Formação de Professores como instituições educativas, cuja principal função consiste em dar resposta às necessidades de desenvolvimento identificadas pelos próprios professores. O caráter local e as próprias características dos contextos de formação de professores, determinam necessidades singulares para os grupos de professores.

Para Klein (1971), o estudo e caracterização das necessidades permitem:

- focalizar a atenção nos problemas mais salientes;

- justificar os programas de ação; 
Beltrán, Isauro y Leite, Betânia: Estudo da determinação das necessidades de professores...

- oferecer informações sobre a situação de entrada que facilitará a avaliação de mudanças posteriores.

A realização de uma pesquisa que nos proporcione elementos para uma análise das necessidades reais, do comportamento real e do comportamento desejado, e a análise dessa diferença de comportamento têm um importante papel na renovação curricular do Ensino Médio. Nesta perspectiva, o presente estudo está implicado com a possibilidade de orientar os processos formativos para contribuir para uma melhor preparação dos professores em serviço.

A seleção de métodos e procedimentos para esta primeira etapa não é, na realidade, uma simples escolha técnica, é na verdade a expressão de exigências que respondam às condições metodológicas mais gerais. A seleção dos instrumentos, na sua totalidade, deve obedecer ao princípio sistêmico, complementarse e oferecer um quadro geral das necessidades diagnosticadas. Marcelo (1992), afirma que as estratégias utilizadas no diagnóstico de necessidades proporcionam informações importantes sobre o modelo de desenvolvimento profissional que assume a instância responsável pelo diagnóstico.

A determinação das necessidades do professor para trabalhar na perspectiva do Nbvo Projeto Pedagógico constitui uma pesquisa orientada para determinar, junto aos professores, com uma especificidade significativa, as competências, habilidades reais e as desejadas para desenvolver com sucesso os propósitos educativos. A investigação tem uma relação com o Programa de Desenvolvimento Profissional, como parte da formação continuada dos professores.

A determinação das necessidades é um momento de grande importância na hora de organizar o Programa de Desenvolvimento Profissional. Toma como base uma caracterização das possibilidades dos professores, seus saberes, como ponto de partida para uma reflexão da prática e a definição das metas. Uma nova Proposta Pedagógica exige uma nova postura profissional dos professores. No entanto, não se pretende uma "mudança por passe de mágica", e sim um processo de reformulação a partir das experiências do professorado, suas competências e saberes, no processo de inovação didática.

$\mathrm{Na}$ determinação das necessidades podem destacar-se quatro etapas: a da pesquisa, a da comparação, a da análise das "brechas" e a da valorização das necessidades. Essas quatro etapas são atividades complexas, que, para serem identificadas, requerem um conjunto de estratégias metodológicas. É necessário, portanto, uma análise global para se obter a maior quantidade de informação possível que permita estruturar o programa formativo.

a) A etapa da pesquisa ( $1^{\text {a }}$ etapa): devemos obter informações de diferentes fontes, analisadas de forma entrecruzada para aumentar sua objetividade. Esta etapa caracteriza-se por uma busca incessante de informação a respeito do comportamento real dos professores na sala de aula, de seu comportamento desejado, de suas preocupações e comprometimentos em relação ao novo Projeto Pedagógico, uma vez que são estas as bases nas quais se sustentarão as demais etapas. 


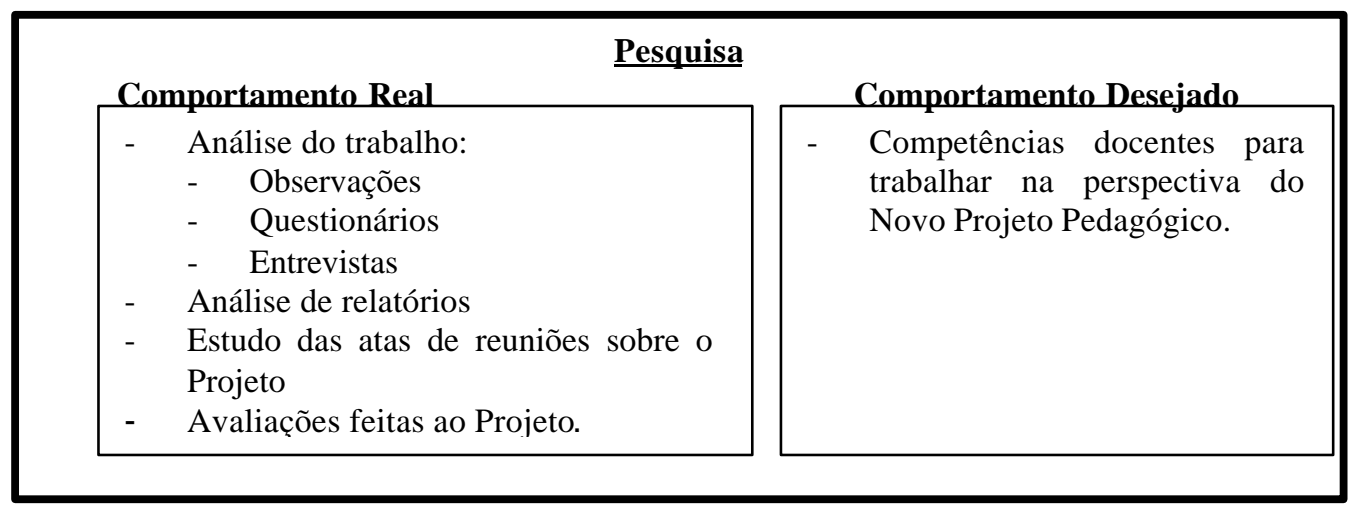

No modelo de necessidades como discrepância ou lacunas, fundamentado nos trabalhos de Kauffman: "uma necessidade é uma discrepância mensurável entre os resultados atuais e os resultados esperados ou considerados convenientes" (Kauffman, 1973, citado em Rodrigues e Esteves, 1993, p. 116).

A existência de necessidades implica na determinação consciente das formas de trabalho do professor e das formas que ele acredita que poderia chegar, por sentir um vazio e a falta de algo entre os seguintes elementos:

- o estado atual ou real (como ele trabalha);

- o estado desejado (o que deve ser), o que pode ser definido segundo critérios, do que poderia ser, o que poderá ser ou o que deve ser.

Roth e Lincoln (citados em Rodrigues e Esteves, 1993, p.16), analisam a função da discrepância entre o estado atual e o estado desejado, identificando cinco modos diferentes de se considerar o estado desejado:

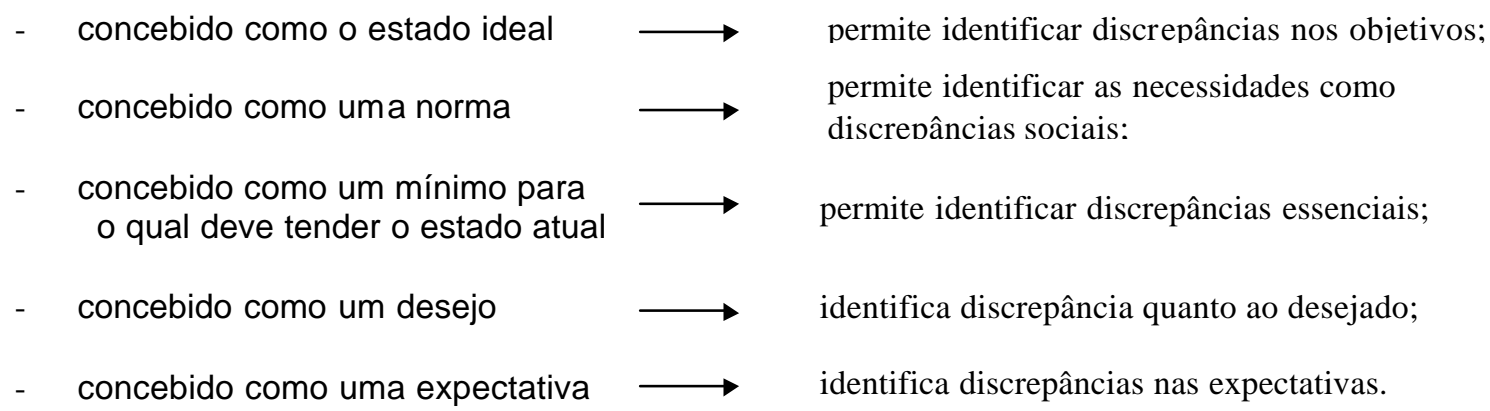

As necessidades podem aproximar-se dos problemas a serem resolvidos, considerando a solução de um problema como processo que permite a passagem de determinadas condições existentes a outras condições desejadas.

b) Na etapa da comparação (2a etapa), entre o estado real e o estado desejado, procuramos os pontos de contato, em termos de necessidades, para determinar as áreas de não correspondência, e definir as 
Beltrán, Isauro y Leite, Betânia: Estudo da determinação das necessidades de professores...

"brechas" entre estes dois estados, o que permitirá uma diferenciação que oriente para uma melhor especificidade do programa formativo.

\section{Comparação}

\begin{tabular}{|c|c|c|}
\hline \multicolumn{2}{|c|}{ Estado Real } & Brecha (necessidades de \\
\hline $\begin{array}{c}\text { Área de conhecimentos, } \\
\text { habilidades e competências } \\
\text { a serem aperfeiçoadas. }\end{array}$ & $\begin{array}{c}\text { Área de correspondência } \\
\text { entre os dois estados. }\end{array}$ & $\begin{array}{c}\text { Área de objetivos a } \\
\text { trabalhar. }\end{array}$ \\
\hline
\end{tabular}

c) A etapa de análise das "brechas" (3a etapa), permite uma maior especificidade e definição dos problemas que podem ser atendidos no Programa de Desenvolvimento Profissional e dos problemas que não se resolvem, mediante estes tipos de programas formativos. A análise das "brechas" exige um trabalho paciente, minucioso e de grande reflexão para poder aproximar-se mais da diferenciação dos problemas. Ligados às determinações das "brechas", é necessário definir as possibilidades e limitações dos processos formativos.

\section{Análise das "brechas"}

Necessidades que podem ser resolvidas no Programa Formativo

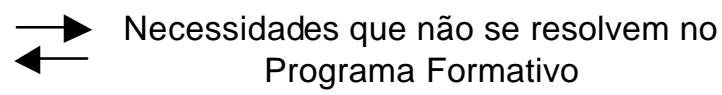

d) a etapa da valorização das necessidades ( $4^{\mathrm{a}}$ e última etapa), permite preparar as condições para a determinação dos objetivos do Programa de Desenvolvimento Profissional.

\section{$\underline{I V}$. Valorização de necessidades}

- Definir precisamente os problemas;

- Reagrupar os problemas em conjuntos específicos;

- Definir plano formativo em função do tempo e das possibilidades.

No presente estudo o diagnóstico de necessidades estará orientado por um conjunto de indicadores com vistas a determinar e caracterizar as competências necessárias para os professores trabalharem na perspectiva do novo Projeto Pedagógico para uma escola do Ensino Médio.

\section{AS ESTRATÉGIAS DE PESQUISA}

\subsection{Objetivos}

Como objetivos do trabalho se definem:

- diagnosticar as necessidades de professores do Ensino Médio para o trabalho segundo a nova Proposta Curricular; 
- propor atividades formativas a partir das necessidades diagnosticadas como Programa de Desenvolvimento Profissional.

\subsection{O contexto empírico da pesquisa}

A pesquisa foi desenvolvida no contexto da Nova Proposta Pedagógica para o Ensino Médio, segundo os pressupostos legais do Ministério da Educação e Cultura, no Centro Federal de Educação Tecnológica do Rio Grande do Norte (CEFET/RN/BRASIL), em relação aos professores do Centro que assumiram esse nível de ensino. O CEFET/RN constitui uma referência de excelência na qualidade da educação no Estado do RN. Caracterizado por sua dinâmica de rupturas com o tradicional, na busca de uma educação pública inclusiva, comprometida com os projetos sociais democráticos, seu reconhecimento ultrapassa os limites do Estado onde está inserido.

O quadro (I), apresenta algumas informações sobre os professores participantes na pesquisa, em total de 67 , distribuídos pelas áreas de conhecimento ${ }^{1}$ e por disciplinas. Como podem ser observadas as médias de anos de experiência nas disciplinas de cada área (14, 15 e 16 anos), mostram que são um conjunto de professores com experiência, e consequentemente com domínio dos conteúdos e das didáticas específicas, constatado nos diferentes relatórios do trabalho do Centro. Assim, também as médias de anos de trabalhos dos professores por área são de 10,3; 8,8 e 8,5 anos. Essa média permite afirmar que estamos na presença de um grupo de professores inseridos na dinâmica da tradição do trabalho, que caracteriza o Centro como instituição de renovação pedagógica.

No geral, estamos face a um grupo de professores comprometidos com a educação pública, pelo que suas necessidades são a expressão desse compromisso e do próprio desenvolvimento profissional.

Quadro I

\begin{tabular}{|c|c|c|c|c|c|}
\hline \multirow[t]{2}{*}{$\begin{array}{c}\text { Área de } \\
\text { conhecimento }\end{array}$} & \multirow{2}{*}{$\begin{array}{c}\text { Total de } \\
\text { professore } \\
\text { s }\end{array}$} & \multicolumn{2}{|c|}{$\begin{array}{c}\text { Professores por } \\
\text { disciplina }\end{array}$} & \multirow{2}{*}{$\begin{array}{l}\text { Média de anos de } \\
\text { experiência na } \\
\text { disciplina }\end{array}$} & \multirow{2}{*}{$\begin{array}{c}\text { Média de anos } \\
\text { de experiência } \\
\text { no CEFET }\end{array}$} \\
\hline & & Disciplina & Total & & \\
\hline \multirow{4}{*}{ CNMT } & \multirow{4}{*}{26} & Matemática & 12 & \multirow{4}{*}{15,7} & \multirow{4}{*}{10,3} \\
\hline & & Química & 05 & & \\
\hline & & Física & 07 & & \\
\hline & & Biologia & 02 & & \\
\hline \multirow{3}{*}{$\mathrm{CHT}$} & \multirow{3}{*}{07} & História & 02 & \multirow{3}{*}{14} & \multirow{3}{*}{8,8} \\
\hline & & Geografia & 04 & & \\
\hline & & Sociologia & 01 & & \\
\hline \multirow{5}{*}{ LCT } & \multirow{5}{*}{34} & $\begin{array}{c}\text { Português/Literatur } \\
\text { a }\end{array}$ & 18 & \multirow{5}{*}{16} & \multirow{5}{*}{8,5} \\
\hline & & Artes & 03 & & \\
\hline & & Educação Física & 06 & & \\
\hline & & Informática & 02 & & \\
\hline & & Inglês & 04 & & \\
\hline
\end{tabular}

\footnotetext{
${ }^{1}$ No Brasil, as Diretrizes Curriculares Nacionais estabelecem as seguintes áreas de conhecimento: Linguagem, seus códigos e suas Teconologias (LCT); Ciências Naturais, Matemática e suas Tecnologias (CNMT); Ciências Humanas e suas Tecnologias (CHT). 


\subsection{Procedimentos Metodológicos}

Segundo as referências teóricas-metodológicas foi construído o seguinte esquema que representa o percurso metodológico para diagnosticar as necessidades de desenvolvimento do professor, por áreas de conhecimento:

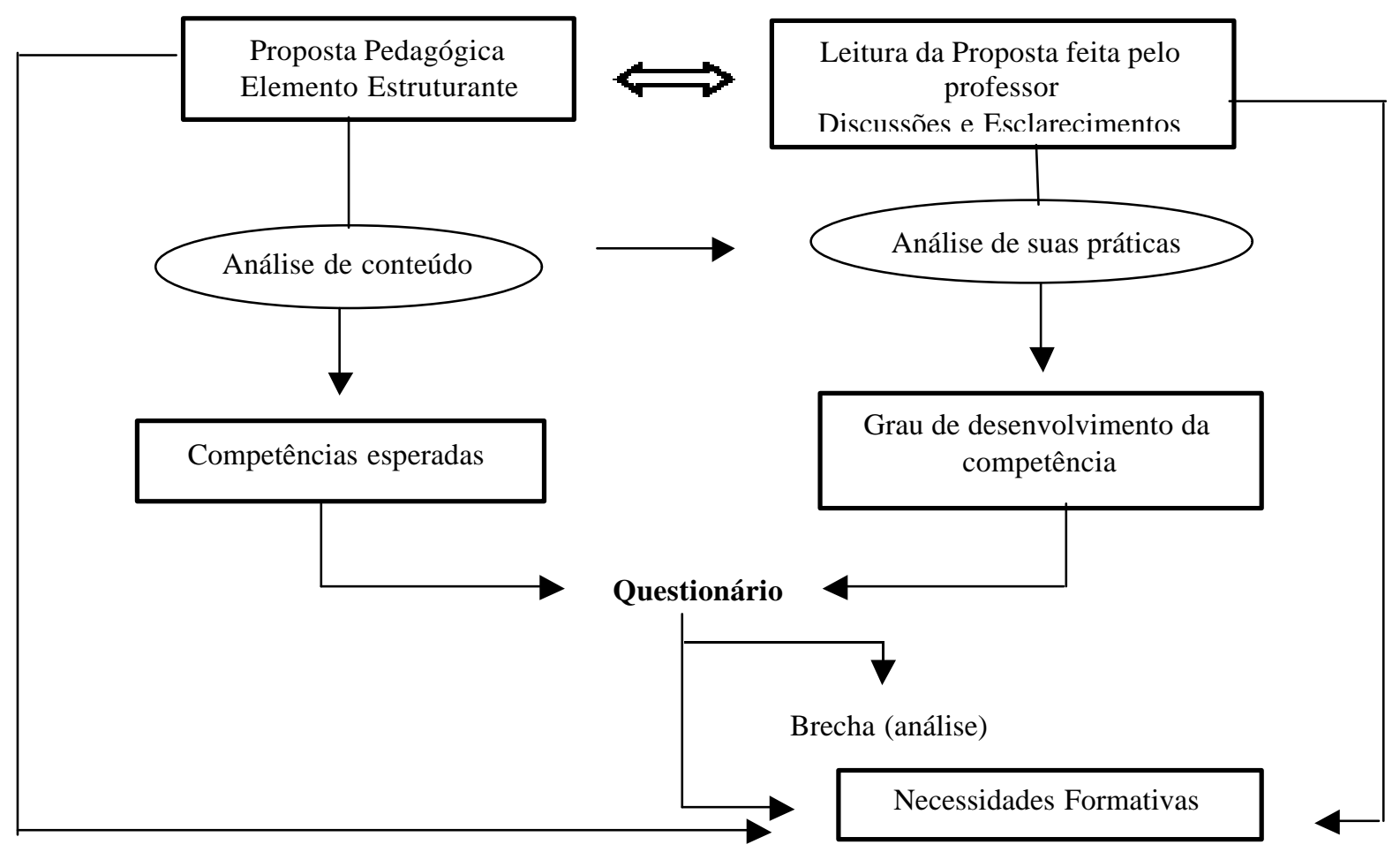

A primeira etapa da pesquisa orientou-se ao trabalho do estudo da Proposta Pedagógica pelos professores de forma individual. Em seguida, foram realizadas reuniões por área de conhecimentos, com a participação do Orientador Pedagógico, de cada área, a fim de estabelecer, a partir da Proposta Pedagógica:

- esclarecimento do conteúdo;

- aspectos positivos, negativos e interessantes;

- dificuldades para instrumentalizar, na prática, a proposta e consequentemente as reformulações necessárias.

A etapa de discussão da Proposta Pedagógica procurou as dúvidas, os "não saberes" nos professores, para a posterior emergência das necessidades no diagnóstico. Como explicam Rodrigues e Esteves (1993, p.22), "As necessidades que cada um expressa não existem, são criadas num dado contexto num duplo sentido: porque o indivíduo as cria quando as expressa e porque expressa as necessidades para as quais o meio de alguma forma contribuiu". As necessidades são produto dos contextos sócio-históricos, são produto da história, em etapas específicas do desenvolvimento, por isso a importância de situar, no concreto, as condições e contextos em que emergem. Em nosso estudo, as mudanças que exigem o trabalho com uma nova Proposta Pedagógica, mobiliza o pensamento dos professores, no sentido de novas necessidades, no contexto conjuntural e evolutivo de sua profissionalização. 
Beltrán, Isauro y Leite, Betânia: Estudo da determinação das necessidades de professores...

De forma paralela os pesquisadores, os orientadores pedagógicos na condição de pesquisadores colaboradores, realizavam com os professores a análise do conteúdo da Proposta para estabelecer as exigências profissionais, em termos de identificar novas competências e, dessa forma, como hipótese de trabalho, estabelecer o estado desejado de formação dos professores para o início do trabalho com a proposta curricular. Nesta perspectiva reconhecemos a impossibilidade das mudanças de uma só vez.

Outros procedimentos foram adotados: a análise das atas das reuniões dos professores por área de conhecimentos, os resultados da análise da Proposta Pedagógica pelos pesquisadores e a partir dessas informações, construída uma proposta de competências necessárias para se trabalhar a nova Proposta Pedagógica. O conteúdo e o sentido das competências foram objeto de discussão nos trabalhos em grupo. Essa questão, considerada de vital importância no estudo, possibilitou aos professores compreender as exigências do novo agir profissional, suas conseqüências e possibilidades, a partir de seus saberes, experiências, etc.

Para caracterizar as necessidades individuais e consequentemente, as necessidades dos professores das áreas de conhecimento, foi preparado um questionário. Apesar das diferentes críticas desse instrumento, o trabalho desenvolvido nas etapas anteriores possibilitou uma maior aproximação dos professores ao sentido de cada competência no questionário. Aplicar o questionário aos professores foi uma das etapas do processo, e portanto, as perguntas do questionário são parte desse processo de construção de sentidos das competências desejadas.

O questionário foi aplicado na reunião dos professores de cada área, na presença dos pesquisadores, para uma nova reflexão da Proposta Pedagógica. A estrutura e o conteúdo do questionário aparecem no quadro a seguir:

\begin{tabular}{|c|c|c|c|c|c|}
\hline \multirow{4}{*}{ Comportamento desejado em termos de competências } & \multirow{2}{*}{\multicolumn{5}{|c|}{$\begin{array}{c}\text { Competência Real } \\
\text { Grau de desenvolvimento }\end{array}$}} \\
\hline & & & & & \\
\hline & \multirow[b]{2}{*}{ B } & \multirow[b]{2}{*}{$\mathbf{R}$} & \multirow[b]{2}{*}{ D } & \multicolumn{2}{|c|}{ Necessidade } \\
\hline & & & & Sim & Não \\
\hline \multicolumn{6}{|l|}{ 1. Organizar o conteúdo em termos interdisciplinares. } \\
\hline \multicolumn{6}{|l|}{$\begin{array}{l}\text { 2. Organizar situações de aprendizagem para a transferência de } \\
\text { conteúdos. }\end{array}$} \\
\hline \multicolumn{6}{|l|}{ 3. Organizar situações de aprendizagem do tipo metacoginitiva. } \\
\hline \multicolumn{6}{|l|}{ 4. Contextualizar o conteúdo. } \\
\hline \multicolumn{6}{|l|}{$\begin{array}{l}\text { 5. Organizar o trabalho dos alunos em grupos para solucionar } \\
\text { problemas. }\end{array}$} \\
\hline \multicolumn{6}{|l|}{ 6. Organizar o ensino por projetos. } \\
\hline \multicolumn{6}{|l|}{ 7. Preparar atividades educativas vinculadas ao conteúdo. } \\
\hline \multicolumn{6}{|l|}{ 8. Preparar situações de aprendizagem para formar competências. } \\
\hline \multicolumn{6}{|l|}{$\begin{array}{l}\text { 9. Preparar situações problemas que orientem os alunos àdefinição } \\
\text { e solução de problemas. }\end{array}$} \\
\hline \multicolumn{6}{|l|}{$\begin{array}{l}\text { 10. Vincular os conteúdos às temáticas transversais, de caráter } \\
\text { social, político, econômico, etc. }\end{array}$} \\
\hline \multicolumn{6}{|l|}{$\begin{array}{l}\text { 11. Organizar os conteúdos segundo os diferentes tipos de saberes: } \\
\text { científico, senso comum, popular. }\end{array}$} \\
\hline $\begin{array}{l}\text { 12. Avaliar competências e habilidades, segundo os novos } \\
\text { pressupostos. }\end{array}$ & & & & & \\
\hline
\end{tabular}


A partir das respostas do questionário, foi feita a análise "da brecha" para cada competência e definidas as necessidades segundo o esquema:

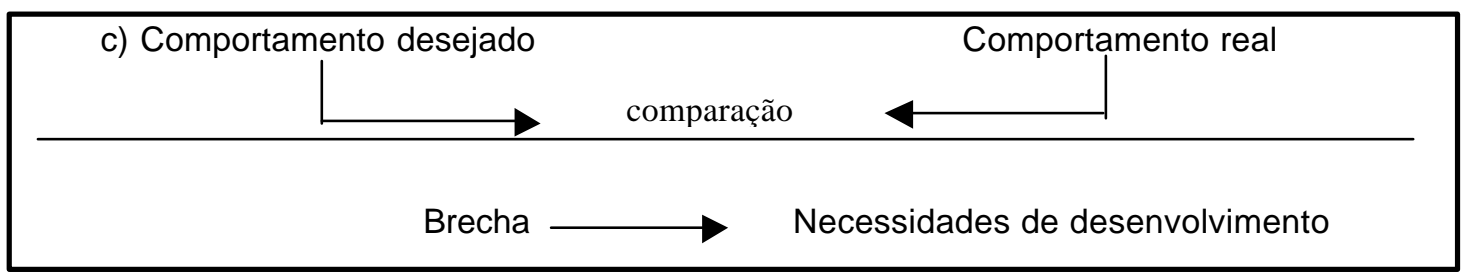

A análise da brecha possibilitou determinar o conjunto de competências, enquanto necessidades de desenvolvimento. Considerando as condições existentes no Centro e o conteúdo das necessidades de desenvolvimento, a análise da brecha permite identificar as necessidades que podiam ser trabalhadas num primer programa formativo, para em seguida, nortear o programa de desenvolvimento profissional.

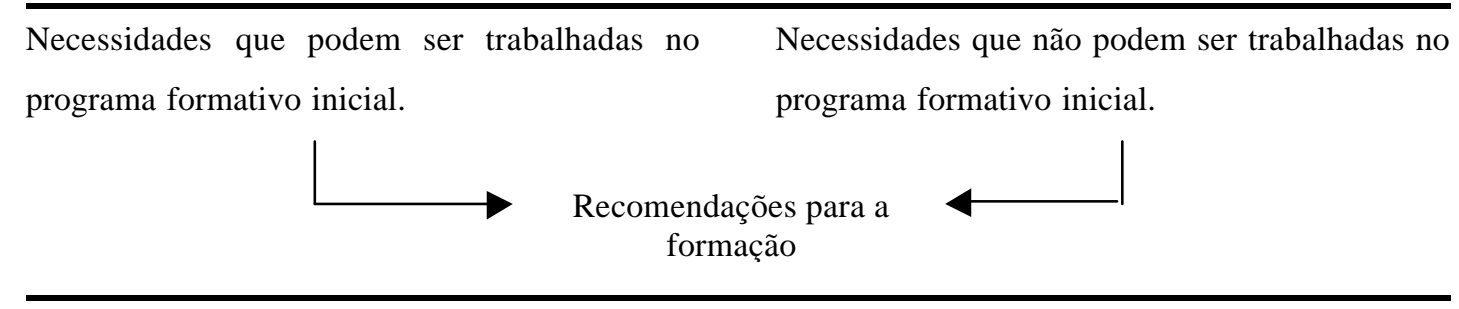

\subsection{Resultados e Proposta Formativa}

As transformações aceleradas na chamada "sociedade do conhecimento", trazem consigo exigências a respeito de novos estilos de trabalho para o professor. Hoje não é o professor/a quem detém o monopólio do saber e a escola deixou de ser o lugar exclusivo para aprender, para o aluno ser educado, como era compreendido no século passado. As novas tecnologias de informação, as novas formas de organização do trabalho obrigam a escola a redefinir seu projeto educativo, para inserir-se no sistema social, numa dinâmica complexa, reconhecendo a necessidade do diálogo com a comunidade e assumindo novos tipos de relações com a comunidade e o conhecimento. A escola, por si só, não pode dar respostas às novas formas de educação dos alunos.

Assim, as necessidades de desenvolvimento dos professores que são determinadas na presente pesquisa procuram aproximar as exigências das novas formas de educar e a formação continuada de professores, e fazer algumas inferências para mudanças, que com "caráter de urgência", devem assumir os cursos de formação de professores, seja na formação inicial ou continuada.

Os resultados dos questionários foram computados para determinar a quantidade de respostas segundo as categorias que correspondem à quantidade de professores, por área, segundo as questões levantadas, ou seja, como eles caracterizam o estado de suas competências e suas necessidades de serem resignificadas em processos de formação continuada. 
Beltrán, Isauro y Leite, Betânia: Estudo da determinação das necessidades de professores...

A partir desses resultados, é possível fazermos as seguintes reflexões. No geral, pode ser observado como o grupo de professores sente novas necessidades para trabalhar numa Proposta Pedagógica que representa uma verdadeira ruptura paradigmática, na própria concepção de educação. Esse dado é de fundamental importância, se considerarmos o referencial empírico, ou seja, o perfil dos professores que compõem o presente estudo.

Organizar projetos de aprendizagem como uma alternativa pedagógica a ser trabalhada, aparece como a necessidade mais expressiva dos professores das três áreas. $O$ trabalho por projetos para o ensino, orientado a formar competências, tem caráter interdisciplinar, ou seja, por área de conhecimentos. Essa forma de organização das disciplinas, focalizando situações problemas contextualizadas, com um objeto de estudo a ser abordado de forma cooperativa entre as disciplinas, a própria organização do tempo e do espaço, se apresenta como uma insuficiência da atividade profissional. Nas diferentes discussões, professores manifestaram interessantes experiências de trabalho com projetos na área do ensino tecnológico, mas as especificidades do ensino médio limitam a transferência mecânica das experiências construídas nesse sentido, de um tipo de ensino para o outro.

O ensino por projetos se liga à contextualização do ser e do saber, na busca de uma aproximação da escola à sociedade, como condição necessária da nova postura que deve assumir na formação de competências que possibilitem ao aluno uma participação cidadã nos projetos sociais dos grupos, favorecendo o crescimento da sua identidade e qualidade de vida. $O$ sucesso ou o fracasso da escola sempre foram discutidos dentro do espaço escolar. Essa visão, atrelada a fortes concepções dos professores, exige uma ruptura de hábitos, para aprender a educar junto com a sociedade, numa perspectiva complexa, do diálogo, do saber escolar com o cotidiano, com a diversidade. No sentido anterior, se explica o fato dos professores manifestarem necessidades para aprender referências para a organização do trabalho interdisciplinar.

A categoria "competência", como um eixo articulador do ensino médio, ainda representa para o conjunto de professores uma problemática. Mais de $70 \%$ dos professores nas áreas de conhecimento manifestam necessidades de referências para trabalhar na perspectiva da formação de competências nos alunos. O termo "competência", por sua polissemia, e pelo próprio desenvolvimento histórico dos sentidos que tem assumido, aparece por vezes contraditório na literatura sobre a temática. Sem uma posição epistemológica do sentido que assume a categoria competência, a sua diferença da habilidade ou o hábito, pouco se poderá avançar nas propostas curriculares que emergem das orientações legais do Novo Ensino Médio. As Agências de Formação de Professores devem prestar mais atenção a essa problemática, pois não podem continuar (des)preparando professores para uma realidade que exige sérias e profundas mudanças. Se bem que formar competências nos alunos é uma tarefa difícil, que mobiliza não só a escola, como também outros fatores sociais, pode, para alguns, ser uma utopia. Concordamos com Paulo Freire, para quem a utopia é um patrimônio dos professores, necessária à luta e ao otimismo por uma educação melhor.

Formar competências nos alunos não constitui uma "moda". Esta revela-se como uma exigência social no milênio atual. Identificar essa problemática como uma necessidade é um sintoma positivo do 
Beltrán, Isauro y Leite, Betânia: Estudo da determinação das necessidades de professores...

compromisso dos professores na busca de uma melhor preparação para assumir a Nova Proposta Curricular para o Ensino Médio no Brasil.

Assim que, outra necessidade que os professores manifestam, em caráter de urgência, para o seu desenvolvimento profissional é a competência de organizar situações de aprendizagem do tipo metacoginitiva. É interessante encontrar nos discursos de muitas escolas e em documentos oficiais sobre a educação, algo que se tem convertido em uma "expressão repetida e com um sentido frágil", essa expressão é "aprender a aprender". Esta competência (aprender a aprender) exige uma aprendizagem metacognitiva, ou seja, concretizar as estratégias e conhecimentos que utilizamos para aprender, questão que possibilita reconstruir os saberes e procurar novas estratégias na formação de uma autonomia, no contexto do grupo social. Os professores manifestam não conhecer como trabalhar fundamentados em referências teóricas, essa qualidade da personalidade dos alunos. Historicamente, a formação de professores pouca atenção tem prestado a essa competência. Muitas vezes, até os professores não conseguem explicitar suas estratégias cognitivas de aprendizagem.

Uma das bases da Proposta Pedagógica se constituiu nas questões sócio-culturais, vinculada à problemática de interesse sócio-cultural, econômico, político, etc. dos grupos de alunos do Centro. As preocupações sócio-culturais procuram uma relação dialética entre o local (singular de contexto) e o global (cultura, política, economia, etc. universais). Dos professores participantes no estudo (73\%, 71\%, 52\%) manifestam necessidade de aprender como trabalhar os pressupostos derivados da orientação do MEC, tais como: a estética da sensibilidade, política da igualdade, ética da identidade, assim como temas de preocupação local. Nesse sentido, os professores da área de Linguagem, seus Códigos e suas Tecnologias, manifestam ter conhecimento das temáticas, já para os professores das outras áreas, os conhecimentos nesse sentido também são limitados.

A preocupação da escola com a cidadania do aluno tem sido sempre uma constante nos discursos. Procura-se agora superar o plano das intenções vagamente declaradas, para buscar caminhos e assumir esse compromisso. As preocupações das bases sócio-culturais do currículo têm caráter transversal e devem ser trabalhadas em todas as disciplinas, na própria postura que assume o Centro enquanto instituição, no vínculo do cognitivo com o afetivo. Isso exige mudanças no próprio estilo de trabalho dos professores, no espaço físico da escola, que ainda continua ao estilo para o qual foi re-estruturada nos séculos passados. Educar para a cidadania supõe abrir-se, inserir-se na comunidade, como parte ativa dos projetos sociais, das problemáticas que envolvem essas comunidades. Esse tipo de competência pedagógica implica assumir a formação do professor com uma base pedagógica, e não só didática* .

Como tem se identificado, o saber com o qual os professores geralmente trabalham está sustentado no conhecimento científico (disciplinar), definidos nos livros e programas escolares. Na Nova Proposta Pedagógica, a contextualização do saber, a formação de competências, o trabalho com projetos, supõem reconhecer diferentes fontes do saber escolar, tais como: o conhecimento científico, o saber do senso comum, o saber popular na procura de um novo senso comum. Reconhecer o papel do conhecimento científico como sistema epistêmico não único, e por vezes com suas limitações, como construção teórica, enquanto modelo é uma tarefa do professor em relação à competência de selecionar e organizar os 
Beltrán, Isauro y Leite, Betânia: Estudo da determinação das necessidades de professores...

conteúdos. É significativo observar como os professores da área de CNMT (84\%), manifestam necessidades para trabalhar esses diferentes saberes. Nessa área, geralmente, o saber científico tem ocupado o topo da hierarquia de saberes, considerando como verdade objetiva e inquestionável, congelados em disciplinas fechadas em suas "torres de marfim". Essa representação sobre o conhecimento científico deve ser modificada. Reconhecer seu valor e potencialidade, suas limitações como modelos e as dificuldades (obstáculos epistemológicos), implica sua aprendizagem, e portanto, seu valor como sistema simbólico.

Uma Proposta Pedagógica que se pretende criativa-crítica, inclusiva, orientada para a construção de uma rova escola, pode fracassar se mantém critérios obsoletos de avaliação. A competência para avaliar competências aparece como uma necessidade dos professores nas três áreas de conhecimento. Uma nova visão do ensino-aprendizagem, da escola dentro da sociedade, numa relação complexa que leva a outra dinâmica da educação, necessariamente precisa de novas formas de avaliar. Neste sentido, algumas questões devem ser consideradas: Como avaliar as competências quando a formação de competências não acontece no marco de um breve tempo? Como fazer uma avaliação democrática, participativa, que ensine a aprender a aprender, capaz de prestar a ajuda, quando necessária, ao aluno? Como avaliar diferente, quando existe algo chamado "vestibular", que muitas vezes se impõe como um obstáculo para a inovação pedagógica das escolas? A necessidade de aprender novas formas de avaliação para os professores das três áreas $(92 \%, 85 \%$ e $88 \%$ ) passa pela necessidade de uma visão sistêmica complexa do processo educativo (Morin, 1999), pela compreensão da aprendizagem como processo complexo, para o qual a escola é um espaço a mais.

\subsection{Elementos de uma proposta de trabalho para a preparação de professores segundo as necessidades por áreas de conhecimento}

Em princípio, foram estudadas na pesquisa, as competências a serem suceptíveis de reflexão na Proposta de Desenvolvimento Profissional de Professores do Centro. A partir dos resultados, se propõem as seguintes atividades:

1. Oficina para a reflexão teórico-metodológica do Ensino por Projetos.

2. Ateliê sobre preparação de situações de aprendizagem para contribuir para formar competências, o que supõe trabalhar também:

- a metacognição;

- a solução de problemas;

- a transferência de conhecimentos;

- a avaliação de competências.

3. Ateliê sobra a preparação de atividades para o trabalho interdisciplinar, que supõe também:

- a contextualização;

- os diferentes tipos de saberes. 
4. Acompanhamento pelos orientadores pedagógicos e reflexões das experiências nos grupos de trabalho, no intuito de construir/reconstruir novos saberes, atitudes, bases das novas competências.

5. Fórum de discussão de resultados de pesquisas sobre a Educação para o Século XXI.

6. Organizar o programa formativo como um programa de inovação didática e curricular pelos professores, como construtores de saberes, competências, e como parte imprescindível do processo de Renovação Curricular, a partir da reflexão, a crítica e a pesquisa, tudo orientada a dita inovação didática com sólidos fundamentos teóricos.

\section{CONCLUSÕES}

A determinação de algumas das necessidades de professores para enfrentar os desafios envolvidos numa Proposta Pedagógica baseada na Lei 9.394/96 e nas DCNEM (Diretrizes Curriculares para o Novo Ensino Médio), apresentou-se como um primeiro passo para procurar estratégias que possibilitem o início de caminhos a construir, marcados pela urgência e pela incerteza, na formação dos professores nesse contexto.

As mudanças que impõem a educação para o século XXI devem ser analisadas sob diferentes ângulos.

Primeiro, reconhecer os grandes esforços que as políticas públicas devem assumir, além dos discursos, para garantir condições necessárias. Fazer reconhecer, pelas autoridades públicas, que uma Reforma Educacional da dimensão das DCNEM implica compromissos, em especial, com o professor, como uma das figuras chaves dessa reforma. É necessário criar as condições para um trabalho profissional, melhorando suas condições de vida, seu prestígio profissional, assegurando o espaço para a reformulação de seu agir profissional para a reconstrução de suas competências a partir de suas experiências, das quais emergem novas necessidades.

Segundo, as próprias instituições, nas quais os professores desenvolvem seu trabalho, devem criar as condições para a construção da nova identidade, exigida enquanto profissional, na dinâmica das relações entre escola e sociedade.

Terceiro, os professores, como profissionais críticos, reflexivos, comprometidos, devem participar ativamente na reformulação de seus hábitos. Um passo é identificar suas necessidades e construir novas estratégias formativas, que possam assegurar novas referências teórico-metodológicas. Tomando como ponto de partida a riqueza das experiências profissionais, reconstruir sua prática, para ajudar a reconstruir a escola. 
Beltrán, Isauro y Leite, Betânia: Estudo da determinação das necessidades de professores...

No presente estudo, os professores manifestam suas necessidades de desenvolvimento, como grupos de profissionais, para fazer frente aos novos desafios vindo de uma renovação mundial dos professores e da educação. Identificar as necessidades não é suficiente, como tampouco criar programas formativos tradicionais marcado pelos mecanismos de treinamento explicando (transmissão) o que deve e como deve ser feito, segundo uma racionalidade fechada. Os novos programas formativos, que emergem das necessidades do objeto da profissão e dos professores devem organizar-se na própria filosofia do estilo profissional que se espera formar nos professores. Não podem organizar-se processos formativos para ensinar como deveria ser, eles mesmos devem ser um marco de propiciar novas experiências, de aprender a aprender, de refletir sobre suas práticas.

O estudo das necessidades se orienta como uma contribuição para se pensar os processos formativos dos professores em serviço, mas não constituem o único critério para esse fim, pois outros fatores influenciam o desenvolvimento profissional dos professores, como as próprias reformas curriculares e as tendências do desenvolvimento profissional, que exigem uma visão a longo prazo da profissão. Como explica Marcelo (1992), os Centros de Formação de Professores não podem ser visto como espécies de "supermercado" que fornece tudo o que os clientes pedem.

\section{BIBLIOGRAFIA}

BLAIR, N e LANGE, R. A model for district staff development. IN: BURKO, P. et.all. (orgs.). Programming for staff development. Londres: Falnes Press - 1990

BURTON, J. K. e MERRIL, P. F. Needs Assessment: goals, needs, and priorities. In: Briggs, L. (org.). Instructional Design. Educ. Tech. Public. 1977.

BRADSHAW, J. The concept of social need. New York Society, março, 1972.

DELORS, J. (Org.). Educação. Um tesouro a descobrir. Relatório da Comissão Internacional sobre Educação para o século XXI. São Paulo: Cortez. Brasília, D. F.: MEC: UNESCO, 2000.

FURIÓ, C. J. Tendências atuares en la formación del professorado de ciencias. Enseñanza de las Ciencias, , 1994. № 12 (2) (p. 188-199).

GARCIA, R. F. Determinacion de las necesidades de aprendizaje (DNA) de los dirigentes. La Habana. Universidad de La Habana, Material Minuo, 1985.

HEWTON, E. School Foused Staff Develapment. London: Falmer, 1988.

KLEIN, S. P. Choosing Needs for Needs Assessment in Procedures for Needs Assessment Education: a symposium. Los Angeles, Center for Study of Evoluation Report, 1971.

MARCELO, C. G. A formação de professores: novas perspectivas baseadas na investigação sobre 0 pensamento do professor. In: Nóvoa, A. (org.). Os professores e a sua formação. Lisboa: Dom Quixote, 1992.

MORIN, E. Complexidade e transdisciplinariedade: a reforma da universidade e do ensino fundamental.Natal: EDUFRN. 1999.

NÓVOA, A. (Org.) Os professores e sua formação. Temas de educação. Publicações Dom Quixote, Lisboa, 1992. 
PERRENOUD, P. Práticas pedagógicas, profissão docente e formação: perspectivas sociológicas. Lisboa: Dom Quixote, 2001.

PORLÁN, A. R. Teoria del conocimento, teoria de la enseñanzay desarrolho professional. Las concepciones epistemológicas de los profesores. Tesis Doutoral. Universidad de Sevilla, España.

RAMALHO, B. L. e NUÑEZ, I. B. Relatório Consultoria ao Centro Federal de Educação Tecnológica do RN (CEFET/RN). Material Mimeo. Natal, 2001.

RODRIGUES, Ângela e ESTEVES, Manoela. A análise das necessidades na formação de professores. Lisboa: Porto Editora, LDA, 1993.

ZABALZA, M. A. Planificação e desenvolvimento curricular na escola. Lisboa: edições ASA, 1998.

* (p. 22) Supõe-se a Pedagogia como o saber educar, na relação da escola com toda a sociedade, e não só no espaço da sala de aula, como sustenta a Didática. 


\title{
Contactar
}

Revista lberoamericana de Educación

\author{
Principal OEI
}

